\section{Microbiological Evaluation of Different Irrigation Protocols on Root Canal Disinfection in Teeth with Apical Periodontitis: An In Vivo Study}

\author{
Nestor Cohenca1, Lea Assed Bezerra Silva², Raquel Assed Bezerra Silva², \\ Paulo Nelson-Filho ${ }^{2}$, Carlos Heilborn ${ }^{3}$, Evandro Watanabe ${ }^{4}$, Maria Conceição \\ Pereira Saraiva ${ }^{2}$
}

\begin{abstract}
The present in vivo study was designed to evaluate the efficacy of apical negative pressure irrigation (ANP), passive ultrasonic irrigation (PUI) and positive pressure irrigation (PP) in the reduction of intracanal bacteria of dogs' teeth with pulp necrosis and apical periodontitis. Eighty root canals were randomly distributed into 3 experimental and 2 control groups according to the irrigation delivery system: group ANP $(n=20)$, group PUI $(n=20)$, group PP $(n=20)$, group PC (positive control - sterile saline irrigation; $n=10)$ and group NC (negative control - vital pulps not subjected to bacterial inoculation; $n=10$ ). The first sample (S1) was collected at baseline, and the second sample (S2) was collected after the disinfection protocols. All samples were seeded in culture media for anaerobic bacteria. CFU counts were analyzed statistically by the Kruskal-Wallis, Dwass-SteelCritchlow-Fligner post-hoc and Chi-square followed by Tukey like multiple comparisons for proportions $(\alpha=0.05)$. All experimental groups were effective in reducing $\mathrm{Gram}$-positive bacteria compared with PC $(p<0.05)$. Regarding the reduction of Gram-negative bacteria, group ANP was significantly better than PP $(p<0.05)$. No statistically significant difference could be found between PP and PUI ( $p>0.05)$. In dog's teeth with apical periodontitis, the use of ANP and PUI can be considered promising disinfection protocols as both delivery systems promoted a significant bacterial reduction.
\end{abstract}

\author{
'Department of Endodontics \\ and Pediatric Dentistry, School \\ of Dentistry, University of \\ Washington, Seattle, WA, USA \\ ${ }^{2}$ Department of Pediatric Dentistry, \\ Ribeirão Preto School of Dentistry, \\ USP - University of São Paulo, \\ Ribeirão Preto, SP, Brazil \\ ${ }^{3}$ Department of Endodontics, \\ Universidad del Pacífico, \\ Asunción, Paraguay \\ ${ }^{4}$ Department of Restorative \\ Dentistry, Ribeirão Preto School of \\ Dentistry, USP - University of São \\ Paulo, Ribeirão Preto, SP, Brazil
}

Correspondence: Profa. Dra. Lea Assed Bezerra da Silva, Avenida do Café, S/N, Monte Alegre, 14040-904 Ribeirão Preto, SP, Brasil. Tel: +55-16-36024138. e-mail: lea@forp.usp.br

Key Words: root canal disinfection, irrigation, passive ultrasonic irrigation, apical negative pressure.

\section{Introduction}

The foundation of successful endodontic therapy is based on the removal of all pulpal tissue, dentinal debris, bacteria and their endotoxins from the root canal (1). Toxic metabolites and byproducts released from microorganisms present within the root canal system diffuse into the periapical tissues and elicit inflammatory responses accompanied with bone resorption (2). Recognizing the predominant role of microorganisms in pulpal and periapical pathosis, endodontic treatment is essentially aimed at the elimination of microorganisms from the root canal system. As demonstrated by Sjøgren et al. (3), endodontic success is directly related to the presence or absence of microorganisms before root canal filling.

The ability of an irrigant to be distributed within a closed canal system is dependent on canal anatomy, size and taper of mechanical instrumentation, and type of delivery system (4). The most challenging area remains the apical third due to the complex anatomy and the presence of an apical vapor lock (5). The efficacy of traditional positive pressure (PP) irrigation is directly dependent on the depth of needle penetration and volume of irrigation (6). However, as efficiency increases by placing the needle closer to the apical foramen, the chance of extrusion of the solution is higher (7), resulting in severe periapical tissue damage and postoperative pain (8). In order to overcome this critical limitation, new delivery systems have been developed, demonstrating better and safer irrigation. Among these new irrigation and activation systems, passive ultrasonic irrigation (PUI) (9-11) and apical negative pressure (ANP) irrigation (12-14) have been shown to promote an effective removal of debris and reduction of intracanal bacteria. De Gregorio et al. (4) compared both systems and found that ANP delivered the irrigant predictably to working length (WL) while PUI caused significantly more penetration of irrigant into lateral canals but not at WL.

Based on the enhanced cleaning and disinfection properties that these systems have demonstrated individually in previous reports, the present in vivo study was designed to compare the efficacy of ANP, PUI and PP, in the reduction of intracanal bacteria of dogs' teeth with apical periodontitis.

\section{Material and Methods}

Eighty root canals from second and third maxillary premolars and second, third, and fourth mandibular premolars of 12-month-old mongrel dogs were selected for this study. All animal procedures conformed to the 
applicable ethical guidelines and regulations of the Animal Research Ethics Committee, University of São Paulo, Brazil and based on the protocol recommended by the International Organization for Standardization (15). All teeth were examined clinically and radiographically before starting the study to confirm the maturation of the roots and absence of disease. A detailed flowchart of the methodology is presented on Figure 1.

Animals were pre-anesthetized with an endovenous injection of Neozine $(1 \mathrm{mg} / \mathrm{kg}$ body wt.; Aventis Pharma, São Paulo, SP, Brazil) 15 min before the operative procedures and then anesthetized with an endovenous injection of tiletamine hydrochloride: zolazepam hydrochloride (Zoletil 50, $0.1 \mathrm{~mL} / \mathrm{kg}$ body wt.; Virbac do Brazil Ind. e Com., São
Paulo, SP, Brazil) to facilitate the passage of an endotracheal tube. Inhalation anesthesia with Isoflurane (Abbott Laboratories, St. Laurent, OC, Canada) was delivered using an inhalation anesthesia apparatus (Takaoka KT-20; Takaoka Ind. e Com., São Paulo, SP, Brazil). Throughout the duration of the operative procedures, the animals were maintained on isotonic saline solution $(0.9 \% \mathrm{NaCl}$; Glicolabor Indústria Farmacêutica, Ribeirão Preto, SP, Brazil).

Thirty-five teeth (70 root canals) were coronally accessed with \#2 round diamond burs complemented with tapered diamond burs (K. G. Sorensen, São Paulo, SP, Brazil) under copious water cooling. Upon removal of the pulp tissue, root canals were left exposed to the oral cavity for 7 days to allow microbial contamination. After

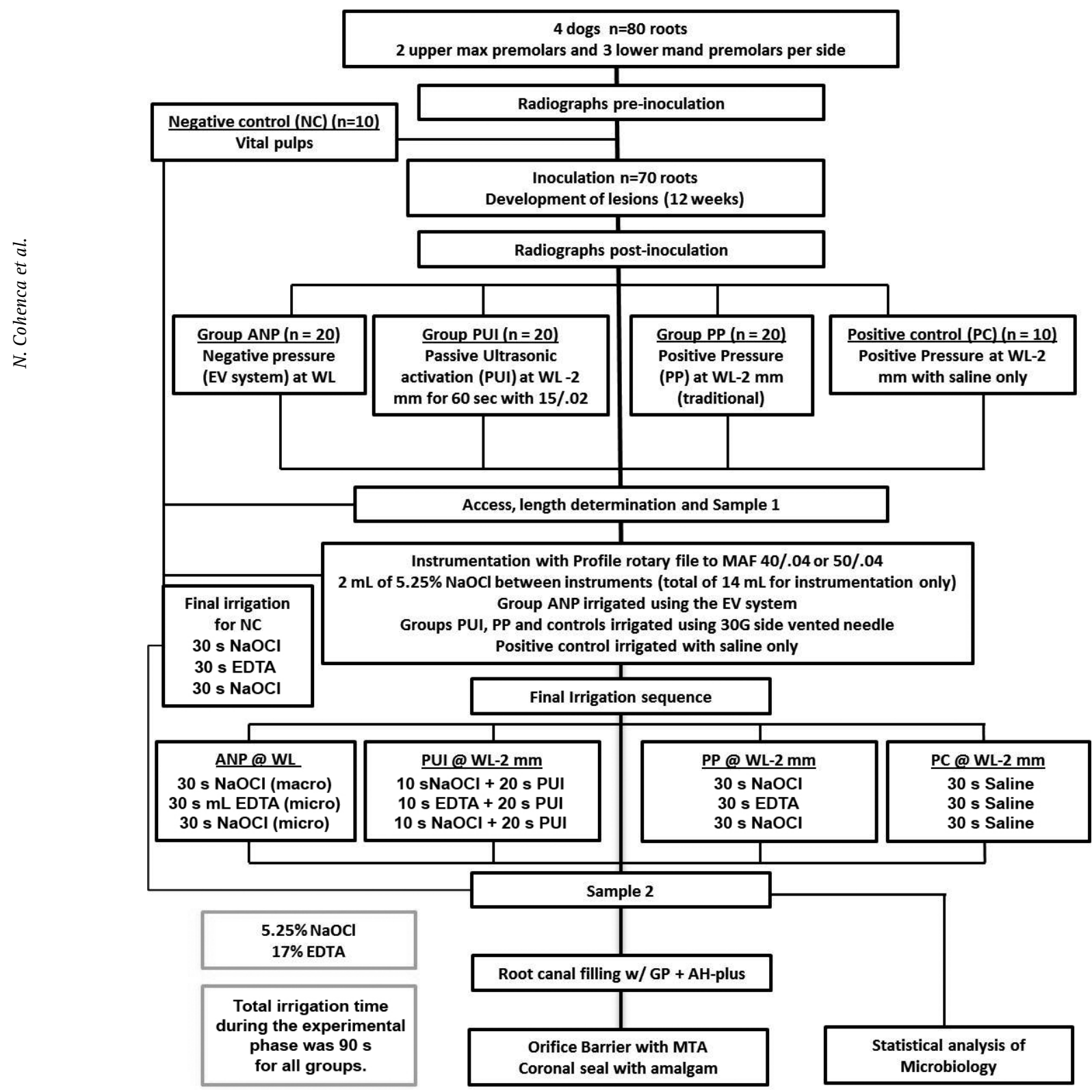

Figure 1. Flowchart of study methodology. 
the inoculation period, the coronal access was sealed with zinc oxide-eugenol cement (S. S. White, Rio de Janeiro, RJ, Brazil) to induce apical periodontitis, according to the protocol of Leonardo et al. (16). Based on previous studies using the same inoculation technique in mature dogs' teeth, the development of apical periodontitis occurs within 40 to 60 days (17). Accordingly, radiographs were taken at 15 days until periapical radiolucencies were observed, indicating the development of apical periodontitis. Once the lesions were radiographically visible, the 80 root canals were randomly assigned to 3 experimental groups and 2 control groups, according to the irrigation delivery system: group ANP ( $n=20$ root canals): apical negative pressure irrigation; group PUI ( $n=20$ root canals): passive ultrasonic irrigation; group PP ( $n=20$ root canals): conventional positive pressure irrigation; Positive control (group PC) included 5 teeth (10 root canals) in which canals were irrigated using positive pressure irrigation and sterile saline; Negative control (group NC) included 5 vital teeth (10 root canals) that were not previously opened for the inoculation process.

All groups were tested in each animal, and the experimental protocols were performed in alternate quadrants in a randomized manner. All teeth were isolated with a rubber dam, and the operative field was disinfected with 30\% hydrogen peroxide until no bubbling of the peroxide occurred. All surfaces were then coated with iodine tincture and allowed to dry.

Temporary restorations were removed from groups ANP, PUI, PP and PC and the root canals were irrigated with sterile saline. Sterile cotton pellets were then used to dry the pulp chamber prior to sampling. Using a sterile tuberculin syringe and a $30 \mathrm{G}$ needle (Max-i-Probe; Dentsply/Tulsa Dental, New York, NY, USA), $0.5 \mathrm{~mL}$ of Liquid Dental Transport Media (LDTM) (Anaerobic Systems, Morgan Hill, CA, USA) was inserted into the canals at $1 \mathrm{~mm}$ short of the estimated root canal length. The fluid was then agitated with a size 20 sterile stainless steel file. Any excess of LDTM in the chamber was removed so that only the root canals remained filled. The LDTM was then soaked from the canals with a sterile fine paper point (Mynol; Block Drug Corp., Jersey City, NJ, USA) placed at $1 \mathrm{~mm}$ short of the estimated root canal length and immediately transferred to the LDTM vial. This constituted the first sample (S1) for groups ANP, PUI, PP and $\mathrm{PC}$. Teeth assigned to the negative control were accessed and the presence of a vital pulp was confirmed. Sample of root canals was performed using the same methodology described above. All samples were immediately submitted to the laboratory.

The WL was established $1 \mathrm{~mm}$ short of the radiographic apex and confirmed using an electronic apex locator (Root ZX; J Morita Corp. Kyoto, Japan). All root canals were instrumented to WL using Profile rotary files to master apical file (MAF) of $40 / .04$ or 50/.04, based on the size of the canal and the pre-instrumentation gauging. During the sequential instrumentation, $2 \mathrm{~mL}$ of $5.25 \%$ sodium hypochlorite was used between instruments (total of 14 $\mathrm{mL}$ per canal).

Once instrumentation was completed, each root canal was irrigated following a specific protocol according to the group assignment. Group ANP was irrigated using the EndoVac system (EndoVac; Discus Dental, Culver City, CA, USA) according to the manufacturer's recommendations and incorporated 2 main phases: macroirrigation and microirrigation. The final irrigation sequence was performed with 30 s $5.25 \% \mathrm{NaOCl}$ (macro), 30 s 17\% EDTA (micro) and 30 s $5.25 \% \mathrm{NaOCl}$ (micro). Group PUI was irrigated using $30 \mathrm{G}$ side vented needle $2 \mathrm{~mm}$ short of the $\mathrm{WL}$, followed by passive ultrasonic activation at WL-2 $\mathrm{mm}$ using specifically designed Irrisafe tips (Satelec, Acteon Group, Merignac, France) mounted on a P5 Neutron XS Ultrasonic Unit (Satelec) at power setting 10, as recently recommended by Jiang et al. (18). The final activation sequence was performed with 30 s $5.25 \% \mathrm{NaOCl}, 30$ s 17\% EDTA and 30 s $5.25 \% \mathrm{NaOCl}$. The solution was replenished in between each sequence as recommended by van der Sluis et al. (19). Root canals assigned to group PP were irrigated using 30G side vented needle and traditional positive pressure at WL-2 $\mathrm{mm}$. The final irrigation followed the same sequence and time as described for groups ANP and PUI.

Root canals from group PC were irrigated with sterile saline using $30 \mathrm{G}$ side vented needle and positive pressure at WL-2 mm. Root canals were irrigated in three cycles of $30 \mathrm{~s}$ each. Teeth assigned to group NC (vital teeth) were irrigated following the same sequence and irrigating solutions as those of group PP. In order to minimize the variables to the delivery system only, the final irrigation sequence and exposure time were the same for all experimental groups.

All root canals were dried with sterile paper points, irrigated with $2 \mathrm{~mL}$ of $5 \%$ sodium thiosulfate, to neutralize the $\mathrm{NaOCl}$, followed by sterile saline and dried with sterile paper points. Using a sterile tuberculin syringe and a $30 \mathrm{G}$ needle, $0.5 \mathrm{~mL}$ of Liquid Dental Transport Media (LDTM) was inserted into the canals at WL. The fluid was then agitated with a size 20 sterile stainless steel file. Any excess of LDTM in the chamber was removed so that only the root canals remained filled. The LDTM was then soaked from the canals with a sterile fine paper point placed at WL and immediately transferred to the LDTM vial. This constituted the second sample (S2) for experimental and control groups. All samples were immediately submitted to the laboratory.

After all canals were sampled, a final irrigation with $5.25 \% \mathrm{NaOCl}$ was performed and canals were then dried with sterile paper points. Root canals were filled with guttapercha and AH-Plus (Dentsply-De Trey, Konstanz, Germany) 
sealer using lateral condensation technique. Periapical radiographs were taken to evaluate the length and density of the apical seal. Upon completion of the root canal filling, orifices were sealed with MTA (ProRoot ${ }^{\oplus}$ MTA; Dentsply Tulsa, Tulsa, OK, USA) and the coronal accesses were restored with amalgam alloy (Sybraloy; Kerr Corporation, Orange, CA, USA). Throughout the experimental phase, dogs were daily monitored for signs of pain associated with the dental procedures and medicated as necessary.

For microbiologic processing, all bacteriological samples were diluted in saline until reaching $1 / 10,1 / 100,1 / 1,000$ and $1 / 10,000$ final concentrations. Next, $50 \mu \mathrm{L}$ of each dilution were seeded using the Westergren technique in the following culture media: Brucella Sheep Blood Agar without Cysteine, which is non-selective and promotes the total growth of Gram-negative and Gram-positive microorganisms, and Brucella Laked Blood Kanamycin with Vancomycin and Agar (Becton Drive, Franklin Lakes, NJ USA), which is a specific media for the Gram-negative development. The dishes were placed in an anaerobiosis jar containing an atmosphere generator (Probac; São Paulo, SP, Brazil) and were incubated at $37{ }^{\circ} \mathrm{C}$ for 10 days. After the incubation period, the number of colony forming units (CFU) was counted with a stereomicroscope

Table 1. Descriptive analysis of microbiological counts $\left(10^{-3}\right)$ for Gram-negative $(\mathrm{G}-)$ and Gram-positive $(\mathrm{G}+)$ anaerobic microorganisms at baseline and after treatments

\begin{tabular}{|c|c|c|c|c|c|c|c|}
\hline & & \multicolumn{3}{|c|}{ Baseline } & \multicolumn{3}{|c|}{ After treatment } \\
\hline & & Median & Q1-Q3* & Min-Max & Median & Q1-Q3* & Min-Max \\
\hline \multirow{4}{*}{ G- } & $\mathrm{ANP}^{\mathrm{a}}$ & 146.0 & $3.12-320.0$ & $0.0-2800.0$ & 0.0 & $0.0-0.0$ & $0.0-0.0$ \\
\hline & $\mathrm{PUl}^{\mathrm{a}}$ & 25.6 & $1.16-216.0$ & $0.0-1280.0$ & 0.0 & $0.0-0.0$ & $0.0-2.32$ \\
\hline & PPab & 0.78 & $0.06-13.0$ & $0.0-200.0$ & 0.0 & $0.0-160.0$ & $0.0-20.0$ \\
\hline & $\mathrm{PC}^{\mathrm{b}}$ & 132.0 & $60.0-600.0$ & $0.0-7600.0$ & 10.0 & $1.12-27.2$ & $1.1-31.6$ \\
\hline \multirow{4}{*}{$\mathrm{G}+$} & ANPa $^{a}$ & 106.0 & $12.0-880.0$ & $0.1-5528.0$ & 0.0 & $0.0-0.0$ & $0.0-0.1$ \\
\hline & $\mathrm{PUI}^{\mathrm{a}}$ & 16.8 & $1.0-120.0$ & $0.0-496.0$ & 0.0 & $0.0-0.0$ & $0.0-0.8$ \\
\hline & $\mathrm{PP}^{\mathrm{a}}$ & 12.4 & $2.3-26.8$ & $0.6-1640.0$ & 0.0 & $0.0-0.6$ & $0.0-152.0$ \\
\hline & $\mathrm{PC}^{\mathrm{b}}$ & 32.0 & $0.5-400.0$ & $0.0-800.0$ & 7.2 & $1.6-41.2$ & $0.8-172.4$ \\
\hline
\end{tabular}

$\mathrm{ANP}=$ apical negative pressure irrigation; $\mathrm{PUI}=$ passive ultrasonic irrigation; $\mathrm{PP}=$ positive pressure irrigation; $\mathrm{PC}=\mathrm{Positive}$ control. * Q1 = first quartile; Q3 = third quartile. Different superscript letters indicate statistically significant difference.
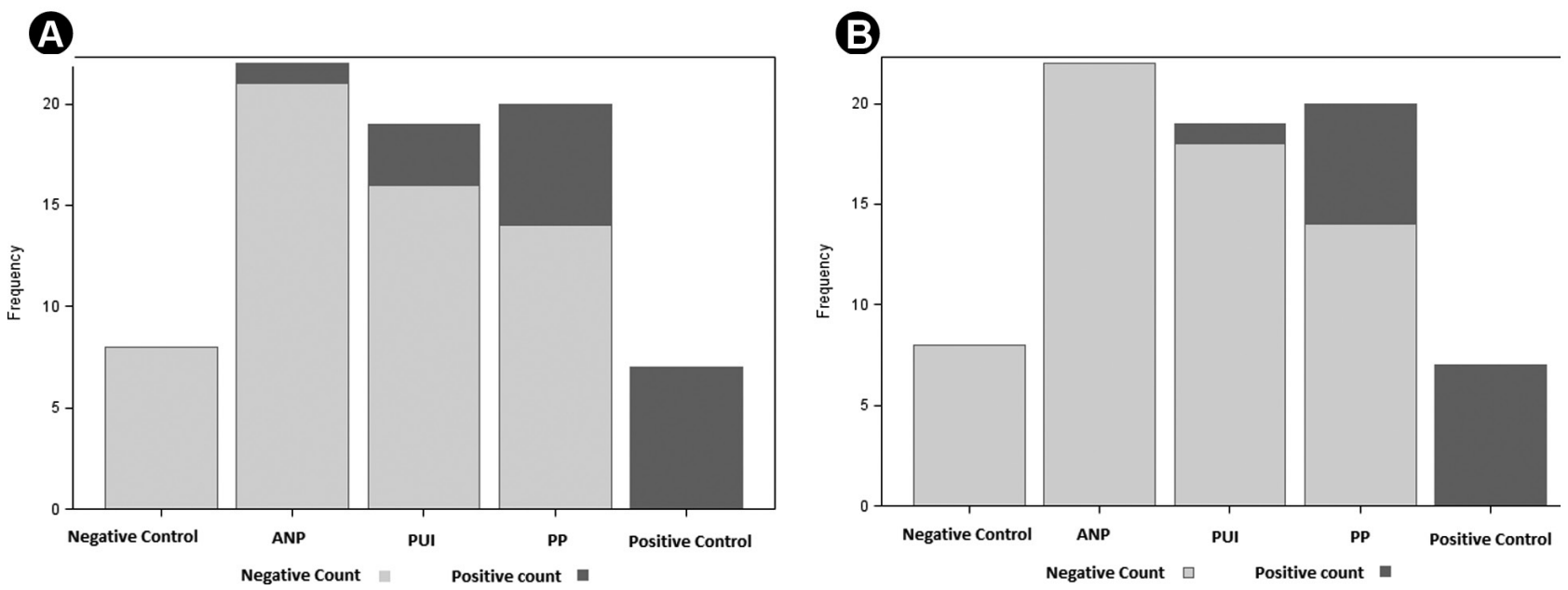

Figure 2. Frequency of counts of negative and positive cultures of Gram-negative (A) and Gram-positive (B) anaerobic microorganisms after treatments. $\mathrm{ANP}=$ apical negative pressure irrigation; $\mathrm{PUl}=$ passive ultrasonic irrigation; $\mathrm{PP}=$ positive pressure irrigation. 
(Nikon, Tokyo, Japan). The CFU count of Gram-negative microorganisms, obtained in the culture media Brucella Laked Blood Kanamycin Vancomycin Agar, was subtracted from the total CFU count obtained in the Brucella Sheep Blood Agar without Cysteine, thereby obtaining indirectly the CFU quantity of Gram-positive microorganisms. Data were analyzed statistically using the Kruskal-Wallis, DwassSteel-Critchlow-Fligner post-hoc and Chi-square followed by Tukey like multiple comparisons for proportions. The significance level was set at 5\% for all analyses.

\section{Results}

Table 1 shows the descriptive analysis of Gram-negative and Gram-positive anaerobic microorganisms at baseline and after the treatments. Percentage reduction of bacterial counts among groups were statistically different for both Gram-negative $(p<0.001)$ and Gram-positive $(p<0.001)$ anaerobic microorganisms. Post-test analysis revealed that among Gram-positive anaerobes, statistically significant differences were observed between all experimental groups and group PC (saline) $(p<0.05)$. For Gram-negative anaerobes statistically significant differences were only observed between groups ANP and PC (saline) $(p<0.05)$ and between groups PUI and PC (saline) $(p<0.05)$.

All samples obtained from group NC were noncultivable at $\mathrm{S} 1$ and $\mathrm{S} 2$, demonstrating the lack of microbial contamination.

The effect of treatment can also be observed when considering the reduction of bacterial counts as measured by frequency of negative cultures of Gram-negative and Grampositive bacteria (Fig. 2). Chi-square test showed reduction to be statistically significant among all experimental groups $(p<0.001)$. Tukey like multiple comparisons for proportions among proportions for counts of Gram-negative and Gram-positive microorganisms showed that the treatments were statistically different from saline for both types of microorganisms, meaning that PC had higher frequency of both strains than the experimental groups. Moreover, among Gram-negative cultures, root canals irrigated with ANP differed significantly from those irrigated with traditional PP $(p<0.05)$. There was no statistically significant difference between PUI and PP ( $p>0.05)$.

\section{Discussion}

The ultimate outcome of endodontic treatment is the health of the periradicular tissues. Infection control is essential for obtaining periapical repair and therefore the primary goal of endodontic therapy should be to decrease the microbial load to a level that enables tissue healing (12). A clear correlation has been demonstrated between healing after endodontic treatment and negative cultures obtained before root filling (3). Although still methodologically challenging, studies focusing on negative culture outcomes are shorter in duration and require smaller populations than follow-up outcome studies. Polymerase chain reaction (PCR) is a very sensitive technology using molecular genetic approaches to identify uncultivable species. Yet, molecular genetic methods detect dead microbes, thus culture techniques remain important in endodontic microbiology (20). The present study used a microbial culture technique in an in vivo experimental model, which reproduces more accurately the clinical situation than ex vivo or in vitro methods. In this specific condition, the effect of irrigation systems and fluid dynamics has been tested, thereby it should take into account the presence of the periradicular tissues surrounding the root surface and the pressure of tissue fluids.

Physical principles within a closed-canal system impose a serious limitation to fluid dynamics and irrigant penetration to the apical third when using positive pressure irrigation $(4,5)$. It has been recommended that when using this conventional system, the needle must be placed to within $1 \mathrm{~mm}$ from working length to enable fluid exchange (21). However, this procedure may lead to extrusion of $\mathrm{NaOCl}$ into periradicular tissues (22). Another factor is the presence of an apical vapor lock resulting from the organic decomposition of $\mathrm{NaOCl}$, which adversely affects debridement efficacy when using positive pressure irrigation $(4,5)$. On the other hand, in vitro studies demonstrated efficient and predictable irrigation of the apical third with ANP and PUI $(4,14)$. The results of the present in vivo study are consistent with previous reports $(10-12,23)$ demonstrating better disinfection of root canals when using these contemporary irrigation delivery systems. While no significant difference was found between ANP and PUI in bacterial reduction, they were both statistically better than traditional PP irrigation.

According to de Gregorio et al. (4), ANP system (EndoVac) is able to reach working length and this ability might be due in part to the design of the micro-cannula, which eliminates the apical vapor lock. Therefore, this system allows apical exchange of irrigants, improving the cleaning performance. Nielsen and Baumgartner (13) found significantly better results after using EndoVac than conventional irrigation with respect to cleaning the most apical portion of the canal, confirming the present findings.

ANP provided better debridement efficacy compared with PP irrigation in an in vivo study using teeth with vital pulps and completely formed apices indicated for extraction (23). Teeth with vitality were chosen to help reduce the variability of debris present in the matched pairs. In contrast, in the present study the different irrigant techniques were evaluated in dog's teeth with apical periodontitis, which really might potentially contain variable amounts 
of bacterial biofilms and debris. It is known that teeth with pulp necrosis and apical periodontitis represent an infectious and immunoinflammatory process, characterized by a mixed and complex microbiota throughout the root canal system, and this is the most challenging clinical situation for the successful endodontic treatment.

ANP was also shown to be a safe irrigation technique, which does not cause irrigant extrusion (7), and thus does not produce periradicular irritation and provides a favorable healing (24).

Silva et al. (24) performed an in vivo study on dogs' teeth exhibiting incomplete root formation and apical periodontitis, and verified that ANP should be considered a promising disinfection protocol. After histopathological analysis, the periapical region revealed well-structured conjunctive tissue with a dense fibroblast infiltration and it was rich in blood vessels. In most cases, there were no inflammatory cells, and the alveolar bone was normal.

In addition, PUI presented a high capacity of penetration of irrigant into apical part and lateral canals (4), which can explain in part the good performance of this system in the present study regarding reducing microbial load. According to the literature, PUl yields superior debridement of the root $\vec{s}$ canal system, greater efficacy in the release of the irrigating solution along the $\mathrm{WL}$, and greater smear layer removal, compared with PP irrigation $(4,25)$. Further research is needed to investigate the response of periradicular tissue to passive ultrasonic irrigation, compared with ANP and PP.

The findings of the present study confirm the fundamental role of chemomechanical preparation for reaching the main goal of endodontic therapy, that is, to completely eliminate intracanal bacterial populations or at least to reduce them to a level that is compatible with periradicular tissue healing $(1,3)$.

In conclusion, in dog's teeth with pulp necrosis and apical periodontitis, the use of ANP and PUI can be considered as promising disinfection protocols as both delivery systems promoted a significant reduction in the bacterial counts.

\section{Resumo}

0 presente estudo foi conduzido para avaliar a eficácia da irrigação por pressão apical negativa (ANP), irrigação ultrassônica passiva (PUI) e irrigação por pressão positiva (PP) na redução do número de bactérias presentes nos canais radiculares de dentes de cães com necrose pulpar e lesão periapical. Um total de 80 canais radiculares foram aleatoriamente distribuídos em 3 grupos experimentais e 2 grupos controles, de acordo com o sistema de irrigação empregado: grupo ANP $(n=20)$, grupo PUI $(n=20)$, grupo PP $(n=20)$, grupo PC (controle positivo - irrigação com solução salina; $n=10$ ) e grupo NC (controle negativo - tecido pulpar com vitalidade, não submetido à contaminação bacteriana; $n=10$ ). A primeira amostra (S1) foi coletada no início do estudo, e a segunda amostra (S2) foi coletada após a utilização dos protocolos de irrigação. Todas as amostras foram semeadas em meio de cultura para micro-organismos anaeróbios. As contagens de unidades formadoras de colônia (cfu) foram analisadas estatisticamente por meio dos testes de Kruskal-Wallis, pós-teste de DwassSteel-Critchlow-Fligner e teste do qui-quadrado seguido do teste Tukey like para comparações múltiplas $(\alpha=0,05)$. Todos os grupos experimentais foram efetivos na redução de micro-organismos Gram-positivos, comparados ao grupo $P C(p<0,05)$. Com relação à redução de microorganismos Gram-negativos, o grupo ANP foi significantemente melhor que o PP $(p<0,05)$. Não foi possivel observar diferença estatisticamente significante entre os grupos PP e PUI $(p>0,05)$. Conclui-se que, em dentes de cães com periodontite apical, os sistemas de irrigação ANP e PUI podem ser considerados métodos promissores, uma vez que ambos os protocolos promoveram uma redução bacteriana significante.

\section{References}

1. Schilder H. Cleaning and shaping the root canal. Dent Clin North Am 1974;18:269-296.

2. Kakehashi S, Stanley HR, Fitzgerald RJ. The effects of surgical exposures of dental pulps in germ-free and conventional laboratory rats. Oral Surg Oral Med Oral Pathol 1965;20:340-349.

3. Sjøgren U, Figdor D, Persson S, Sundqvist G. Influence of infection at the time of root filling on the outcome of endodontic treatment of teeth with apical periodontitis. Int Endod J 1997;30:297-306.

4. de Gregorio C, Estevez R, Cisneros R, Paranjpe A, Cohenca N. Efficacy of different irrigation and activation systems on the penetration of sodium hypochlorite into simulated lateral canals and up to working length: an in vitro study. J Endod 2010;36:1216-1221.

5. Tay FR, Gu LS, Schoeffel GJ, Wimmer C, Susin L, Zhang K, et al.. Effect of vapor lock on root canal debridement by using a side-vented needle for positive-pressure irrigant delivery. J Endod 2010;36:745-750.

6. Chow TW. Mechanical effectiveness of root canal irrigation. J Endod 1983;9:475-479.

7. Mitchell RP, Baumgartner JC, Sedgley CM. Apical extrusion of sodium hypochlorite using different root canal irrigation systems. J Endod 2011;37:1677-1681.

8. Hülsmann $M$, Hahn W. Complications during root canal irrigation literature review and case reports. Int Endod J 2000;33:186-193.

9. van der Sluis LW, Wu MK, Wesselink PR. The efficacy of ultrasonic irrigation to remove artificially placed dentine debris from human root canals prepared using instruments of varying taper. Int Endod J 2005;38:764-768.

10. Burleson A, Nusstein J, Reader A, Beck M. The in vivo evaluation of hand/rotary/ultrasound instrumentation in necrotic, human mandibular molars. J Endod 2007;33:782-787.

11. Carver $K$, Nusstein J, Reader A, Beck M. In vivo antibacterial efficacy of ultrasound after hand and rotary instrumentation in human mandibular molars. J Endod 2007;33:1038-1043.

12. Cohenca N, Heilborn C, Johnson JD, Flores DS, Ito IY, da Silva LA. Apical negative pressure irrigation versus conventional irrigation plus triantibiotic intracanal dressing on root canal disinfection in dog teeth. Oral Surg Oral Med Oral Pathol Oral Radiol Endod 2010;109:e42-46.

13. Nielsen BA, Baumgartner J. Comparison of the EndoVac System to needle irrigation of root canals. J Endod 2007;33:611-615.

14. Parente JM, Loushine RJ, Susin L, Gu L, Looney SW, Weller RN, et al.. Root canal debridement using manual dynamic agitation or the EndoVac for final irrigation in a closed system and an open system. Int Endod J 2010;43:1001-1012.

15. ISO, Standard, 7405. Dentistry. Preclinical evaluation of biocompatibility of medical devices in dentistry - Test methods for dental materials. In. Geneva, Switzerland: International Organization for Standardization; 1997.

16. Leonardo MR, da Silva LA, Leonardo R de T, Utrilla LS, Assed S. Histological evaluation of therapy using a calcium hydroxide dressing for teeth with incompletely formed apices and periapical lesions. J Endod 1993;19:348-352.

17. Leonardo MR, Almeida WA, Ito IY, da Silva LA. Radiographic and microbiologic evaluation of posttreatment apical and periapical repair of root canals of dogs' teeth with experimentally induced chronic lesion. Oral Surg Oral Med Oral Pathol 1994;78:232-238.

18. Jiang $L M$, Verhaagen $B$, Versluis $M$, Langedijk J, Wesselink $P$, van der 
Sluis LW. The influence of the ultrasonic intensity on the cleaning efficacy of passive ultrasonic irrigation. J Endod 2011;37:688-692.

19. van der Sluis LW, Vogels MP, Verhaagen B, Macedo R, Wesselink PR. Study on the influence of refreshment/activation cycles and irrigants on mechanical cleaning efficiency during ultrasonic activation of the irrigant. J Endod 2010;36:737-740.

20. Nair PN. Abusing technology? Culture-difficult microbes and microbial remnants. Oral Surg Oral Med Oral Pathol Oral Radiol Endod 2007; 104:569-570.

21. Boutsioukis C, Lambrianidis $T$, Kastrinakis E. Irrigant flow within a prepared root canal using various flow rates: a Computational Fluid Dynamics study. Int Endod J 2009;42:144-155.

22. Desai $P$, Himel V. Comparative safety of various intracanal irrigation systems. J Endod 2009;35:545-549.

23. Siu C, Baumgartner JC. Comparison of the debridement efficacy of the EndoVac irrigation system and conventional needle root canal irrigation in vivo. J Endod 2010;36:1782-1785.

24. da Silva LA, Nelson-Filho P, da Silva RA, Flores DS, Heilborn C, Johnson

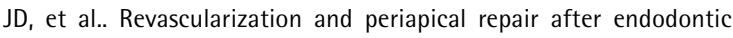
treatment using apical negative pressure irrigation versus conventional irrigation plus triantibiotic intracanal dressing in dogs' teeth with apical periodontitis. Oral Surg Oral Med Oral Pathol Oral Radiol Endod 2010;109:779-787.

25. Malentacca A, Uccioli U, Zangari D, Lajolo C, Fabiani C. Efficacy and safety of various active irrigation devices when used with either positive or negative pressure: an in vitro study. J Endod 2012;38:16221626.

Received February 1, 2013 Accepted August 16, 2013 